\title{
Stability analysis of green innovation in construction enterprises based on evolutionary game
}

\author{
PeiPei $\mathrm{Hu}^{1 *}$ \\ ${ }^{1}$ (School of management, Tianjin University of Technology, Tianjin 300384, China)
}

\begin{abstract}
In order to conform to the trend of ecological economic development, the development of clean, energy saving, environmental protection of green new products has become the primary task of construction enterprises. Based on this, by establishing the game model between suppliers and manufacturers in the construction supply chain, this paper considers the influence of different parameters such as innovation cost, innovation compensation and innovation revenue increment on the choice of green innovation strategy of both enterprises. By solving the replication dynamic equation, the evolutionary stability results show that suppliers and manufacturers choose different decision-making methods according to the revenue, input-output results and the amount of green innovation subsidies given to each other.
\end{abstract}

\section{Introduction}

Since the 21 st century, all countries in the world have actively promoted the development of buildings to be intelligent, energy-saving and green. Green building has become the mainstream development direction of the construction industry, and the green innovation of construction enterprises has received widespread attention. Green innovation refers to the transformation or innovation of processes, technologies, systems and products to minimize the energy use per unit of output, minimize the emission of pollutants ${ }^{[1,2]}$. So green innovation is the primary determinant of green supply chain development ${ }^{[3]}$.

As a key form of enterprise collaborative development, supply chain has different impacts on enterprises' green innovation through upstream and downstream cooperation and competition. Literature [4] uses game theory to study the impact of upstream and downstream enterprises' innovative on the profits of supply chain enterprises from the perspective of technological innovation. Because of the high risk of green innovation, innovation subsidies are usually used as supplementary means to promote the development of green innovation. Literature [5] through the construction of the game model between government and enterprises, it is concluded that the government's green subsidies and carbon tax collection behavior can help enterprises to carry out breakthrough green innovation activities. Literature [6] considers the impact of core enterprises and supporting enterprises on green innovation performance under three different contract conditions, and finds that cost sharing contract can improve the level of green innovation. Therefore, we think that there is a cooperation contract in the supply chain. However, whether the subsidy behavior between suppliers and manufacturers is conducive to green innovation has not been concluded.

Through previous studies, we find that most of the green innovation games are focused on government subsidies, environmental regulation and other aspects, few studies consider the fairness of the game within the enterprise. Therefore, by establishing the game model between suppliers and manufacturers in the construction supply chain, this paper considers the influence of different parameters on the choice of green innovation strategy of both enterprises from the perspective of fairness preference.

\section{Model establishment}

For green innovation, construction enterprises can choose two stratagies: green innovation $\left(\mathrm{S}_{1}\right)$ and non green innovation $\left(\mathrm{S}_{2}\right)$. Because green innovation will reduce the waste and improve the reputation of consumers, so as to improve the economic benefits. If only one party carries out green innovation, under the fair effect, the two parties can require the party who does not carry out innovation to give certain subsidies to the innovator. To sum up, this paper assumes that:

(1) If the supplier and the manufacturer do not carry out green innovation, the normal profits of them are $e_{\mathrm{s}}$ and $e_{\mathrm{m}}, e_{\mathrm{s}}>0, e_{\mathrm{m}}>0$;

(2) If both of them carry out green innovation, the profits of them are $e_{\mathrm{s}}+\alpha_{1} e_{\mathrm{s}}-C_{\mathrm{s}}, e_{\mathrm{m}}+\beta_{1} e_{\mathrm{m}}-C_{\mathrm{m}}$. Among them, $\alpha_{1}, \beta_{1}$ represents the incremental revenue ratio of green innovation for suppliers and manufacturers, $C_{\mathrm{s}}, C_{\mathrm{m}}$ represents the cost of product green innovation for supplier and manufacturer;

(3) When the supplier carries out green innovation but the manufacturer does not, the supplier requires the manufacturer to provide innovation subsidy, so the profit is $e_{\mathrm{s}}+\alpha_{2} e_{\mathrm{s}}-C_{\mathrm{s}}+f\left(\alpha_{2}<\alpha_{1}\right)$. Due to the "free rider" strategy of

* Corresponding author: hupeipei1212@163.com 
the manufacturer, the revenue obtained is higher than the normal revenue, the revenue is $F_{\mathrm{m}}-f\left(F_{\mathrm{m}}>f\right)$;

(4) When the manufacturer carries out green innovation, but the supplier does not, so the profit is $e_{\mathrm{m}}+\beta_{1} e_{\mathrm{m}}-C_{\mathrm{m}}+f\left(\beta_{2}<\beta_{1}\right)$. Because the supplier adopts the "free rider" strategy, the revenue is higher than the normal revenue, the revenue is $F_{\mathrm{s}}-f\left(F_{\mathrm{s}}>f\right)$;

Both sides of the game establish the game payment matrix as shown in Table 1.

Table 1 Payment matrix of suppliers and manufacturers

\begin{tabular}{ccc}
\hline \multirow{2}{*}{ supplier } & \multicolumn{2}{c}{ manufacturer } \\
\cline { 2 - 3 } & $\mathrm{S}_{1}$ & $\mathrm{~S}_{2}$ \\
\hline $\mathrm{S}_{1}$ & $e_{\mathrm{s}}+\alpha_{1} e_{\mathrm{s}}-C_{\mathrm{s}}, e_{\mathrm{m}}+\beta_{1} e_{\mathrm{m}}-C_{\mathrm{m}}$ & $e_{\mathrm{s}}+\alpha_{2} e_{\mathrm{s}}-C_{\mathrm{s}}+f, F_{\mathrm{m}}-f$ \\
$\mathrm{~S}_{2}$ & $F_{\mathrm{s}}-f, e_{\mathrm{m}}+\beta_{2} e_{\mathrm{m}}-C_{\mathrm{m}}+f$ & $e_{\mathrm{s}}, e_{\mathrm{m}}$, \\
\hline
\end{tabular}

\section{Equilibrium analysis}

\subsection{Equilibrium point of evolution process}

It is assumed that the proportion of suppliers and manufacturers choosing green innovation strategy is $\mathrm{x}$ and $y$ respectively. From the above discussion, we can see that the expected benefits of suppliers choosing green innovation and non green innovation strategies are $U_{11}=y\left(e_{s}+a_{1} e_{s}-C_{s}\right)+(1-y)\left(e_{s}+a_{2} e_{s}-C_{s}+f\right) \quad, \quad U_{12}=y\left(F_{s}-f\right)$ $+(1-y) e_{s}$; so the average expected revenue of the supplier is $\bar{U}_{1}=x U_{11}+(1-x) U_{12}$.

The dynamic equation is as follows:

$$
X=\frac{d x}{d t}=x\left(U_{11}-\bar{U}_{1}\right)=x(1-x)\left[a_{2} e_{s}-C_{s}+f+y\left(a_{1} e_{s}-F_{s}-a_{2} e_{s}+e_{s}\right)\right]
$$

In the same way, we can get the dynamic equation of manufacturer's replication is:

$$
Y=\frac{d y}{d t}=y\left(U_{21}-\bar{U}_{2}\right)=y(1-y)\left[\beta_{2} e_{m}-C_{m}+f+x\left(\beta e_{m}-F_{m}-\beta_{2} e_{m}+e_{m}\right)\right]
$$

Using the above two formulas, we can construct a twodimensional dynamic system $\mathrm{W}$ : make $\mathrm{X}=0, \mathrm{Y}=0$, the results are as follows:

Proposition 1 According to the two-dimensional dynamic system $\mathrm{W}$, the balance point is $(0,0),(1,1),(0,1)$ and $(1,0)$. When $\alpha_{1}>\frac{C_{s}-f-e_{s}+F_{s}}{e_{s}}, 0<\alpha_{2}<\frac{C_{s}-f}{e_{s}}$, $\beta>\frac{C_{m}-f-e_{m}+F_{m}}{e_{m}}, 0<\beta_{2}<\frac{C_{m}-f}{e_{m}}$, or $0<\alpha_{1}<\frac{C_{s}-f-e_{s}+F_{s}}{e_{s}}$, $\alpha_{2}>\frac{C_{s}-f}{e_{s}}, 0<\beta<\frac{C_{m}-f-e_{m}+F_{m}}{e_{m}}, \quad \beta_{2}>\frac{C_{m}-f}{e_{m}},\left(\mathrm{x}^{*}, \mathrm{y}^{*}\right)$ is also the equilibrium point of the dynamic system $\mathrm{W}$, $x^{*}=\frac{C_{m}-\beta_{2} e_{m}-f}{\beta_{1} e_{m}-F_{m}-\beta_{2} e_{m}+e_{m}}, y^{*}=\frac{C_{s}-\alpha_{2} e_{s}-f}{\alpha_{1} e_{s}-F_{s}-\alpha_{2} e_{s}+e_{s}}$.

\subsection{Stability analysis of equilibrium point}

Take the partial derivatives of the differential equations of the system $\mathrm{W}$ with respect to $\mathrm{x}$ and $\mathrm{y}$ to further judge the evolutionary stability strategy of the system, the correlation Jacobian matrix is $J=\left[\begin{array}{ll}\frac{\partial X}{\partial x} & \frac{\partial X}{\partial y} \\ \frac{\partial Y}{\partial x} & \frac{\partial Y}{\partial y}\end{array}\right]$,

$\frac{\partial X}{\partial x}=(1-2 x)\left[a_{2} e_{s}-C_{s}+f+y\left(a_{1} e_{s}-F_{s}-a_{2} e_{s}+e_{s}\right)\right]$

$\frac{\partial X}{\partial y}=x(1-x)\left(a_{1} e_{s}-F_{s}-a_{2} e_{s}+e_{s}\right), \quad \frac{\partial Y}{\partial x}=y(1-y)\left(\beta_{1} e_{m}-F_{m}-\beta_{2} e_{m}+e_{m}\right)$,

$\frac{\partial Y}{\partial y}=(1-2 y)\left[\beta_{2} e_{m}-C_{m}+f+x\left(\beta_{1} e_{m}-F_{m}-\beta_{2} e_{m}+e_{m}\right)\right]$.

Proposition 2 We can bring the relevant value into the determinant trace and value to judge the stability of the equilibrium point, if it satisfies $\frac{\partial X}{\partial x}+\frac{\partial Y}{\partial y}<0$, $\frac{\partial X}{\partial x} \times \frac{\partial Y}{\partial y}-\frac{\partial X}{\partial y} \times \frac{\partial Y}{\partial x}>0$, then the equilibrium point is the evolutionary stable point. Because $\left(\mathrm{x}^{*}, \mathrm{y}^{*}\right)$ is brought into the Jacobian matrix and the trace is $0,\left(x^{*}, y^{*}\right)$ is not a stable point. Table 2 only lists the optimal surface expressions for the determinant traces and values for the four equilibrium points.

Table 2 Trace and value of different equilibrium points

\begin{tabular}{c|c|c}
\hline \multirow{2}{*}{$(0,0)$} & $\operatorname{Tr} W$ & $\left(\alpha_{2} e_{\mathrm{s}}-C_{\mathrm{s}}+f\right)+\left(\beta_{2} e_{\mathrm{m}}-C_{\mathrm{m}}+f\right)$ \\
\cline { 2 - 3 } & $\operatorname{Det} W$ & $\left(\alpha_{2} e_{\mathrm{s}}-C_{\mathrm{s}}+f\right)\left(\beta_{2} e_{\mathrm{m}}-C_{\mathrm{m}}+f\right)$ \\
\hline \multirow{2}{*}{$(0,1)$} & $\operatorname{Tr} W$ & $\left(\alpha_{1} e_{\mathrm{s}}-F_{\mathrm{s}}-C_{\mathrm{s}}+e_{\mathrm{s}}\right)+\left(-\left(\beta_{2} e_{\mathrm{m}}-C_{\mathrm{m}}+f\right)\right.$ \\
\cline { 2 - 3 } & $\operatorname{Det} W$ & $\left(\alpha_{1} e_{\mathrm{s}}-F_{\mathrm{s}}-C_{\mathrm{s}}+e_{\mathrm{s}}\right)\left(-\left(\beta_{2} e_{\mathrm{m}}-C_{\mathrm{m}}+f\right)\right.$ \\
\hline \multirow{2}{*}{$(1,0)$} & $\operatorname{Tr} W$ & $\left(-\left(\alpha_{2} e_{\mathrm{s}}-C_{\mathrm{s}}+f\right)\right)+\left(\beta_{1} e_{\mathrm{m}}-F_{\mathrm{m}}-C_{\mathrm{m}}+e_{\mathrm{m}}\right)$ \\
\cline { 2 - 3 } & $\operatorname{Det} W$ & $\left(-\left(\alpha_{2} e_{\mathrm{s}}-C_{\mathrm{s}}+f\right)\right)\left(\beta_{1} e_{\mathrm{m}}-F_{\mathrm{m}}-C_{\mathrm{m}}+e_{\mathrm{m}}\right)$ \\
\hline \multirow{2}{*}{$(1,1)$} & $\operatorname{Tr} W$ & $\left(F_{\mathrm{s}}+C_{\mathrm{s}^{-}} \alpha_{1} e_{\mathrm{s}}-e_{\mathrm{s}}-f\right)+\left(F_{\mathrm{m}}+C_{\mathrm{m}}-\beta_{1} e_{\mathrm{m}-} e_{\mathrm{m}}-f\right)$ \\
\cline { 2 - 3 } & $\operatorname{Det} W$ & $\left(F_{\mathrm{s}}+C_{\mathrm{s}}-\alpha_{1} e_{\mathrm{s}}-e_{\mathrm{s}}-f\right)\left(F_{\mathrm{m}}+C_{\mathrm{m}}-\beta_{1} e_{\mathrm{m}}-e_{\mathrm{m}}-f\right)$ \\
\hline
\end{tabular}

(1) When $0<\alpha_{1}<\frac{C_{s}-f-e_{s}+F_{s}}{e_{s}}, 0<\alpha_{2}<\frac{C_{s}-f}{e_{s}}$, $0<\beta_{1}<\frac{C_{m}-f-e_{m}+F_{m}}{e_{m}}, 0<\beta_{2}<\frac{C_{m}-f}{e_{m}}$, point $(0,0)$ is the evolutionary stability of system $\mathrm{W}$.

(2) When $0<\alpha_{1}<\frac{C_{s}-f-e_{s}+F_{s}}{e_{s}}, 0<\alpha_{2}<\frac{C_{s}-f}{e_{s}}$, $0<\beta_{1}<\frac{C_{m}-f-e_{m}+F_{m}}{e_{m}}, \quad \beta_{2}>\frac{C_{m}-f}{e_{m}}$, point $(0,1)$ is the evolutionary stability of system $\mathrm{W}$.

(3) When $0<\alpha_{1}<\frac{C_{s}-f-e_{s}+F_{s}}{e_{s}}, \quad \alpha_{2}>\frac{C_{s}-f}{e_{s}}$, $0<\beta_{1}<\frac{C_{m}-f-e_{m}+F_{m}}{e_{m}}, 0<\beta_{2}<\frac{C_{m}-f}{e_{m}}$, point $(1,0)$ is the evolutionary stability of system $\mathrm{W}$.

(4) When $\alpha_{1}>\frac{C_{s}-f-e_{s}+F_{s}}{e_{s}}, \alpha_{2}>\frac{C_{s}-f}{e_{s}}$, $\beta_{1}>\frac{C_{m}-f-e_{m}+F_{m}}{e_{m}}, \quad \beta_{2}>\frac{C_{m}-f}{e_{m}}$, point $(1,1)$ is the evolutionary stability of system $\mathrm{W}$. 
(5) When $\alpha_{1}>\frac{C_{s}-f-e_{s}+F_{s}}{e_{s}}, 0<\alpha_{2}<\frac{C_{s}-f}{e_{s}}$, $\beta_{1}>\frac{C_{m}-f-e_{m}+F_{m}}{e_{m}}, 0<\beta_{2}<\frac{C_{m}-f}{e_{m}}$, point $(0,0)$ and (1,

$1)$ is the evolutionary stability of system W.

(6) When $0<\alpha_{1}<\frac{C_{s}-f-e_{s}+F_{s}}{e_{s}}, \quad \alpha_{2}>\frac{C_{s}-f}{e_{s}}$, $0<\beta_{1}<\frac{C_{m}-f-e_{m}+F_{m}}{e_{m}}, \quad \beta_{2}>\frac{C_{m}-f}{e_{m}}$, point $(0,1)$ and $(1$,

0 ) is the evolutionary stability of system W.

\subsection{Evolution result analysis}

By analyzing the evolutionary game process of manufacturers and suppliers in different situations, the phase diagrams of six evolutionary results are shown in figure 1 . Based on the above analysis and phase diagram, six different cases are analyzed.

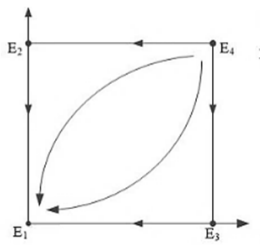

(1)

(4)

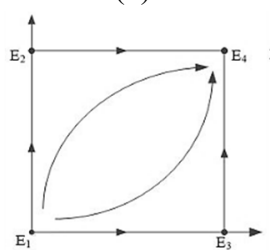

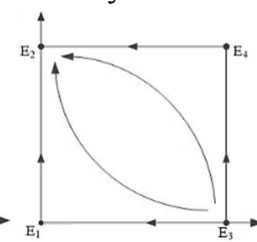

(2)

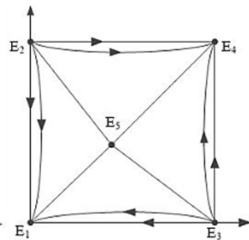

(5)

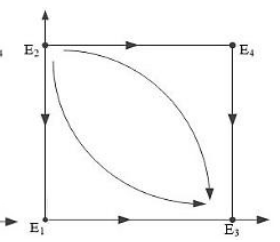

(3)

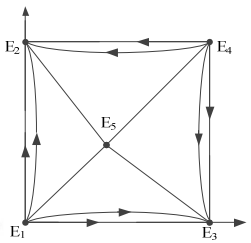

(6)
Fig.1 Phase diagram of system $\mathrm{W}$ evolution

Case 1 When the supplier and manufacturer carry out green innovation separately, if the input cost of green innovation is higher than the social benefits and economic benefits, they will choose not to carry out green innovation. As shown in figure $1(1)$, at this time, $(0,0)$ is the stable point of evolutionary game.

Case 2 Because the high incremental income and the low innovation subsidy from "free riding", the supplier chooses not to carry out green innovation. Because the incremental benefits and innovation subsidies are higher than the input costs, the manufacturer chooses to carry out green innovation. As shown in Figure $1(2),(0,1)$ is the stable point

Case 3 The supplier chooses to carry out green innovation when the incremental income and innovation subsidy may be higher than the input cost. If the income from joint innovation is less than that from free riding strategy, the manufacturer is more inclined to choose not to carry out green innovation. As shown in figure 1(3), (1, 0 ) is the stable point.

Case 4 When the economic benefits of joint innovation gradually increase until they are greater than the benefits of free riding, both suppliers and manufacturers will choose green innovation with the improvement of social and economic benefits. As shown in Figure 1(4), $(1,1)$ is the stable point.
Case 5 Suppliers and manufacturers choose not to carry out green innovation because it is difficult for them to compensate their input costs for the benefits from green innovation alone. However, with the improvement of economic benefits, the benefits from their joint green innovation are higher than the incremental benefits from their own "free riding" behavior. If one party chooses to carry out green innovation, the other party will follow it, otherwise they will not carry out green innovation. As shown in figure $1(5),(0,0)$ and $(1,1)$ are the stable points.

Case 6 On the contrary to case 5 , if the benefits of green innovation by suppliers and manufacturers are higher than the input cost and the benefits of joint green innovation are lower than the input cost, $(0,0)$ and $(1,1)$ are the stable points.

\section{Conclusion}

Based on the evolutionary game analysis between suppliers and manufacturers in the construction supply chain, this paper studies the behavior decision-making of green innovation between them. The results have some significance for the choice of green innovation strategies among construction enterprises: (1) when enterprises have the same green innovation benefits, suppliers and manufacturers who can effectively control the cost are more likely to go green innovation; (2) if both of them are likely to carry out green innovation, when the incremental revenue of the supplier is much higher than that of the manufacturer, the manufacturer will choose to give up the product innovation; (3) when there is only one party carries out green innovation, the other enterprise choose to "free riding" strategy to earn additional revenue, if the incremental revenue from joint innovation is greater than the total revenue from free riding after deducting the innovation cost, the enterprises that do not carry out green innovation will follow the path of innovation (4) the innovation subsidies given by enterprises to each other play an important role in it, if the agreed amount of subsidies is too high, the incremental benefits of "free riding" can hardly offset its costs, it will force enterprises to turn to green innovation.

\section{References}

1. Bai Y, Wang J Y, Jiao J L. A framework for determining the impacts of a multiple relationship network on green innovation[J]. Sustainable Production and Consumption, 2021, 27: 471-484.

2. Abdullah M, Zailani S, Iranmanesh M, et al. Barriers to green innovation initiatives among manufacturers: the Malaysian case[J]. Review of Managerial Science, 2016, 10(4): 683-709.

3. Meng Q, Wang Y, Zhang Z, et al. Supply chain green innovation subsidy strategy considering consumer heterogeneity[J]. Journal of Cleaner Production, 2021, 281: 125199.

4. Wang L L, Chen G H. A game analysis of on the technology innovation of chain-tyle industrial cluster[J]. China management science, 2016, 24(1): 151-158. 
5. Xu J Z, Guan J, Zhu X Y. Evolutionary game analysis on impacts of government regulation on enterprises environmental innovation mode selection[J]. Operations Research and Management Science, 2017. 26(9): 68-77.

6. Sun J H, Zhang H B. A Research on Collaborative Innovation Cooperation Strategy of Green Supply Chain[J]. Industrial Engineering Journal, 2020, 23(4): 53-60+92. 